\title{
A CRÍTICA DA RAZÃO UTILITÁRIA E A FUNDAMENTAÇÃO ONTOLÓGICA DAS ESCOLHAS METODOLÓGICAS NO PARADIGMA DA DÁDIVA
}

\author{
Alexandre Simão de Freitas *
}

\begin{abstract}
Resumo. Neste artigo, procura-se demonstrar que a crítica da razão utilitária, processada pelo paradigma da dádiva contribui para uma reflexão radical das escolhas metodológicas no âmbito das ciências sociais. Ao buscar interrogar o vínculo social, o paradigma da dádiva aciona um terceiro nível de análise da ação social: o nível das redes e das relações. No âmbito ontológico, isso permite que as teorias sociológicas transcendam, simultaneamente, as aporias do holismo e do individualismo metodológico, abrindo novas vias de descrição, explicação, interpretação e avaliação do funcionamento das regras do social.
\end{abstract}

Palavras-chave: razão utilitária, ontologia, epistemologia das redes.

"Em que medida o destino das ciências sociais está ligado ao do princípio de razão?" Com esta questão aparentemente simples, o editor da Revue du M.A.U.S.S., Alain Caillé (2001), coloca em cena um certo tipo de Aufhebung sociológica que serve para demarcar drasticamente os desafios teóricos e metodológicos enfrentados pelas ciências sociais nestes tempos de volatilidade do pensamento crítico. Ancorado nas chaves descritivas do que se convencionou chamar, na França, de "o terceiro paradigma", construído a partir das

\footnotetext{
Doutor em Sociologia pela Universidade Federal de Pernambuco (PPGS/UFPE), linha de pesquisa Exclusão, Cidadania e Processos de Mudança.

Artigo recebido em 29 jul. 2003; aprovado em 30 ago. 2003.
} 
contribuições fundantes de Marcel Mauss, o paradigma da troca de dádivas vem buscando uma redescrição complexa e multidimensional da ação social.

A crítica dos difusores do "paradigma do dom" assume um tom drástico em relação às tradições de pesquisa estabelecidas: a Sociologia estaria perdendo, simultaneamente, legitimidade científica e prestígio acadêmico por não conseguir se libertar dos "compromissos epistemológicos com a racionalidade instrumental que é a base do pensamento moderno de inspiração cartesiana" (Capes-Cofecube, 2002, p.03).

Colonizada pelo abstracionismo das grandes categorias, a Sociologia se veria marcada pela imprecisão na abordagem dos fenômenos sociais concretos, e mais especificamente na explicação dos motivos práticos dos sujeitos sociais.

Essa situação estaria sendo motivada pela generalização, no interior das ciências sociais e humanas, em geral, e na Sociologia, em particular, de um certo imaginário utilitarista. Entendendo-se por utilitarismo a confluência de dois postulados inter-conectados: um postulado teórico que afirma que as ações sociais são motivadas pelos cálculos racionais dos sujeitos interessados; e, um postulado normativo no qual a maximização da felicidade constitui o critério de justiça das ações, normas ou leis (Caillé, 2001, p. 32).

Nesse sentido, o paradigma da dádiva busca combater as antinomias da razão utilitária moderna, questionando-a nos âmbitos teórico, prático e normativo. Com isso, o paradigma desencadeia uma forma de problematização sui generis dos tipos de normatividade social e das formas de sociabilidade vigentes nos sistemas sociais contemporâneos.

Ao rejeitar simultaneamente a influência das metodologias individualistas e holistas, desenvolvidas nas ciências sociais e humanas, o paradigma da troca de dádivas redireciona o olhar da investigação para a natureza mesma do vínculo social, apontando um caminho sugestivo para se transcender, a um só tempo, tanto as aporias derivadas dos racionalismos abstratos, quanto dos relativismos pluralistas em vigor. Ou seja, introduz-se um outro (terceiro) nível de 
análise nas ciências sociais e humanas (para além do indivíduo e da sociedade): as relações e as redes (Martins, 2001).

Esse tipo de análise da relação social pressupõe uma espécie de arquegenealogia da sociabilidade nas sociedades contemporâneas, cuja pretensão consiste em localizar o "ser social" sem se deixar seduzir por qualquer tipo especial de "substância" (personificadora da vida associativa), mas que também não pretende se deixar enredar nas malhas de um "plano da vida" formado por sujeitos atomizados e naturalizados.

No entanto, o objetivo deste trabalho não é o de apresentar ou interrogar os fundamentos desse modelo. A intenção mais ampla consiste, sobretudo, em trazer à tona uma reflexão em torno do tipo de "engajamento ontológico" que fundamenta a teoria da troca de dádivas, analisando as conseqüências desse engajamento para o "trabalho da sociologia" quando da investigação dos problemas sociais concretos. O ponto de ancoragem da discussão reside em uma questão nuclear: o problema da determinação ou indeterminação ontológica da realidade enquanto vetor fundamental para a compreensão do funcionamento do social-histórico e, mais especificamente, do vínculo social.

O paradigma da dádiva introduziu uma nova "lógica" de compreensão do "social", deslocando as explicações essencialistas e fenomenalistas da sociedade e do próprio conhecimento para uma apreensão diferencial e complexa. Nesse âmbito, o real é, antes de tudo, relacional. Até mesmo os "estilos de vida" individual resultariam de um campo social onde o relacional é a força motriz, uma vez que

para melhorar continuamente a sua coerência interna, cada pessoa deve chegar à compreensão das relações que lhe são positivas e úteis, que reforçam sua autonomia, porém dar-se conta, também, de que o útil não é tanto aquilo que lhe convém, individual e isoladamente, mas, sobretudo, o que a torna solidária com o mundo natural e social simultaneamente. (Villasante, 2002, p. 91)

Trata-se então de uma forma de compreender o "ser social" que exige um aprofundamento dos próprios modelos de investigação sobre os quais se apóiam os chamados métodos de pesquisa social, uma vez que se considera que "o princípio de razão é incapaz de 
dar conta da essência da dádiva, dado que esta é justamente a procura de um para-lá do princípio da razão suficiente” (Caillé, 1997, p.143).

Nesse contexto, é importante reter o sentido que se está atribuindo, nesse texto, ao termo método. Segundo Sartori (1997, p. 5), para "saber pensar" nas ciências sociais e humanas não há técnica que baste, ou seja, "para saber pensar são necessários método e lógica, método lógico - em uma palavra metodologia”. Esse tipo de proposição implica, portanto, uma diferenciação no interior das discussões metodológicas, uma vez que é preciso distinguir

as posições epistemológicas (pressupostos sobre as bases do conhecimento) da metodologia de pesquisa (uma análise teórica que define um problema de pesquisa, e como a pesquisa deveria proceder) e esta, por sua vez, do método específico (ou seja, da estratégia ou técnica efetivamente adotada). (Henwood, 1996, p. 31)

Nessa perspectiva, a reflexão que se pretende fazer distanciase claramente dos "tratados de metodologia" que se ocupam das técnicas de investigação e tratamento de dados, mas que em geral tendem a não distinguir o método da investigação do método da reflexão. Ao fazer essa delimitação não temos a intenção de desclassificar ou desconsiderar o valor daquele tipo de reflexão metodológica nas ciências sociais. Buscamos um outro tipo de enquadramento que visa, antes de tudo, analisar "as condições para a crença" em uma teoria e os limites para sua análise prática (Lacey, 1998). Justifica-se, assim, a ênfase dedicada à problemática ontológica enquanto cenário mais amplo para se pensar as escolhas metodológicas nas ciências sociais, em geral, e, na sociologia, em particular. A intenção é mostrar que, no estudo dos fatos sociais, a justificação de um método não pode prescindir de uma decisão ontológica.

\section{As determinações ontológicas do "Ser Social": a idéia de uma metametodologia ${ }^{1}$}

O termo ontologia, na modernidade, assumiu o antigo objeto da metafísica: a questão do ser ou, mais especificamente, as determinações do ser (Castoriadis, 1999). Na tradição moderna, a 
compreensão do ser passou a ser deduzida formalmente de um conceito e não mais abstraído da experiência. ${ }^{2}$ Essa diferenciação que está no centro mesmo do pensamento moderno gira em torno da seguinte questão: como é possível adquirir um conhecimento dos tipos de coisas que existem que seja digno de credibilidade? A resposta a esta questão deságua inevitavelmente na delimitação dos princípios metodológicos a serem seguidos na investigação científica. Situação que faz da ontologia um campo de reflexão de fundamental importância para as ciências sociais.

De acordo com Oliva (1999, p. 18), é cada vez mais evidente o fato de que as ciências sociais e humanas vêm há séculos disputando os critérios a partir dos quais devem ser identificados e hierarquizados os "seres" do mundo da vida social. Isso acontece porque o "ser das coisas sociais" não "depende de se poder ver aquilo a que se atribui existência”. As escolhas ontológicas jogam um papel central na apresentação dos resultados da observação em torno do que existe, pois "o que dizemos que existe, como existe, contraindo tal ou qual tipo de relação, não é função de atividade puramente constatativa”. Logo,

as teorias sociais estão infestadas de termos com Democracia, Exército, Nação, Culto, Revolução, Religião, Estado, Instituição, Cultura, etc. Em torno de que tipo de ente deve gravitar o estudo dos 'fatos sociais'? Das partes, dos coletivos ou do Todo? Quando se promove o estudo comparativo entre os enfoques centrados nas unidades individuais e os baseados na concessão de vida autônoma a coletivos ou a totalidades facilmente se comprova que há fossos intransponíveis entre os diferentes estilos de teoria social produzidos pelas chamadas ciências sociais. Que tipo de teoria se mostra mais científica - a que se organiza como estudo de fenômenos localizados no plano da existência dos indivíduos ou a que privilegia fatores que pertencem a uma esfera da realidade supraindividual? (Oliva, 1999, p. 21-22)

As disputas ontológicas não se restringem ao terreno especulativo da filosofia política, interferindo ativamente no trabalho das ciências sociais. Uma discussão nem sempre óbvia para os que atuam nesse campo, mas que se revela de modo exemplar nas disputas em torno dos modelos de racionalidade que devem fundamentar os trabalhos produzidos nessa área. 
Não casualmente, portanto, tanto os pós-modernistas que partem de Nietzsche e Heidegger, como os neopragmatistas e o próprio Habermas têm problematizado ativamente a idéia de fundamentação última da realidade; todos empenhados em uma fundamentação pósmetafísica. ${ }^{3} \mathrm{O}$ próprio tema recorrente da auto-superação da metafísica, na passagem da filosofia da consciência para a da linguagem, acabou por introduzir, mais uma vez, a disputa entre realistas e não-realistas (Vattimo, 2001, p. 21).

Ao admitir que "isto", ou seja, a "realidade" do mundo não pode ser reduzida à percepção do sujeito (o próprio sujeito que percebe não gozaria de qualquer estatuto ontológico sólido quando comparado com suas percepções do "real"), desencadeou-se uma crise generalizada de legitimidade das narrativas modernas de conhecimento (Lyotard, 1993), gerando um niilismo difuso que se apresenta como a marca de "realidade" das várias escolas de pensamento existentes na atualidade. As próprias "teorias do pósmoderno" emergiram como uma espécie de auto-consciência agônica da razão iluminista, anunciando o cansaço crepuscular de uma época em crise. $^{4}$

Vale lembrar, então, que não são apenas os problemas sociais que mudam, mas a maneira de colocá-los que sofrem uma alteração radical. A questão mais ampla passa a ser decidir em que medida o apelo "pós-moderno" à relatividade dos saberes e ao seu envolvimento com a distribuição do poder social, de um lado, e a recusa do "princípio de realidade", por outro, não estaria produzindo um efeito perverso de deslegitimação da própria atividade científica, reduzindo o "fazer ciência" a uma espécie de ontologia ilusionista que se realiza através dos "jogos das interpretações" em um conjunto de movimentos arbitrários do sujeito. O que explicaria, dentre outras coisas, o déficit de confiança no pensamento sociológico contemporâneo.

Nesse sentido, a simples substituição do modelo representacionista do conhecimento por um modelo de comunicação que põe as trocas lingüísticas mediadas intersubjetivamente no lugar de uma objetividade ontológica da experiência do ser, fazendo da linguagem "condição irrecusável de todo acesso ao real, mediação necessária de todo sentido e de toda validade" (Oliveira, 2000, 
p. 7), não é condição suficiente para se construir um "modelo elegante" que seja capaz de mostrar como funciona o nosso mundo e que conhecimento podemos extrair desse conhecimento.

Explicitar os fundamentos ontológicos do "ser social" permanece como um desafio para as teorias sociológicas que objetivam descrever, explicar, interpretar e avaliar adequadamente a relação entre os modos de manifestação empírica da sociabilidade dos atores e o mundo das estruturas e funções.

Em outras palavras, para que a teoria social não seja uma obra de ficção interpretativa, ela não pode se abster de problematizar os fundamentos da sociedade, sob o risco de tornar estéril o campo de interrogações que a alimenta: o que há no mundo da vida social? Um primeiro desafio, nesse caso, consiste em identificar o método que aborde a existência da sociedade, ultrapassando os modelos essencialistas e fenomenistas de objetivação do "dado" social. Pois, enquanto o primeiro modelo, opera com definições essenciais ancoradas em deduções sistemáticas que visam instalar um discurso absoluto com base no princípio da suficiência lógica das proposições e na determinação exaustiva do objeto investigado, manifestando assim um modelo axiomático a partir do qual o conhecimento emergiria absoluto e verdadeiro, porque completamente imune à contradição; o modelo fenomenista, ancorando-se na física e no método matemático-experimental, instala o problema da fundação do conhecimento válido a partir dos dados oriundos da experiência. Uma experiência quase transcendental porque transparente ao espírito e homogênea à coisa. ${ }^{5}$

Articulados, esses dois modelos, contribuem para provocar um deslocamento do "ser social" ora para o plano da exterioridade, ora para o plano da interioridade. Nos dois casos, a investigação da existência social se vê obstruída por ontologias redutoras (de corte marcadamente holista ou individualista) incapazes de captar os traços fundamentais dos mecanismos da sociabilidade. Essas ontologias naturalizadas emergem do paradigma mentalista da razão utilitária moderna que pensa a subjetividade desde o enfoque idealizador de uma consciência transmutada em espelho da "realidade". $\mathrm{Na}$ interpretação neopragmatista de Richard Rorty (1994), trata-se da 
subsunção da ontologia pela epistemologia, fazendo com que a natureza do conhecimento seja atrelada ao modo pelo qual a mente é capaz de construir representações verdadeiras sobre o que está fora da mente.

Entre as questões principais que a epistemologia buscaria responder estariam as seguintes: o que é o conhecimento? Como nós o alcançamos? A definição padrão, no primeiro caso, é a de que o conhecimento seria crença verdadeira justificada.

Esta definição parece plausível porque, ao menos, dá a impressão de que para conhecer algo alguém deve acreditar nele, que a crença deve ser verdadeira, e que a razão de alguém para acreditar deve ser satisfatória à luz de algum critério, pois alguém não poderia dizer conhecer algo se sua razão para acreditar fosse arbitrária ou aleatória. (Grayling, 2002, p. 1)

Todavia, essa definição de conhecimento deve ser entendida ainda como uma análise do conhecimento no sentido proposicional, pois ela é obtida perguntando que condições têm de ser satisfeitas quando queremos descrever alguém como conhecendo algo. Ou seja, ao dar a definição, enunciamos o que esperamos que sejam as condições necessárias e suficientes para a verdade da afirmação "S sabe que $p$ ", onde "S" é o sujeito epistêmico, o suposto conhecedor, e " $p$ " a proposição. ${ }^{6}$

O passo seguinte, para responder à segunda questão, teve muito a dever ao duelo do mecanicismo materialista baseado na clareza e evidência das ciências matemáticas com o subjetivismo do pensamento racional autônomo. $\mathrm{O}$ vetor paradigmático, aqui, seria a crítica kantiana da razão, uma vez que na sua Crítica da Razão Pura, Kant teria levado essa discussão às últimas consequiências, substituindo "o conceito substancial da razão da tradição metafísica pelo conceito da razão cindida nos seus momentos e cuja unidade não é mais que formal. Mas (que) desempenha também o papel de um juiz supremo, mesmo perante a cultura como um todo" (Habermas, 1990, p. 29).

Não obstante, sua eficácia auto-legitimadora, a razão kantiana passou da condição de inquiridora para inquirida, pois com o avanço da modernidade ganharia relevo uma nova antropologia do homem 
que, sugerindo um novo "modo de ser", estava ancorada não mais nos pontos fixos da essência e do fenômeno, julgados pelas estruturas a priori da razão, mas no acontecimento histórico. A consciência da historicidade passou a afetar, simultaneamente, o mundo das coisas e as sociedades dos homens, autorizando um novo modelo de racionalidade que busca no "devir" o sentido de uma experiência aberta e lacunar. Como argumenta Domingues:

À diferença dos tempos plats da idade das luzes, o século XIX foi sacudido por um conjunto de fatos e acontecimentos que levaram os filhos do século a experienciar um sentimento novo em relação à história e a adotar uma atitude nova em relação ao tempo. (...) Ponto de ruptura e inflexão, o século XIX desencadeou a segunda era de revoluções da modernidade, de alcance tão profundo quanto a expansão comercial no século XVI e as inovações científicas do século XVII. Estendendo-se a um tempo à ciência e à técnica, e ainda ao modo de organização das sociedades dos homens, o resultado foi a instalação da chamada civilização técnico-científico-industrial, da qual estamos longe de ter o justo recuo para fazer a justa avaliação da constelação de suas implicações (Domingues, 1991, p. 267-268).

Essa nova forma de problematização que toma o tempo como índice ou modo de ser das coisas fez com a história emergisse como o modo de conhecimento referencial em torno do qual se erigiria toda uma constelação de ciências particulares. ${ }^{7}$ A experiência da temporalidade possibilitou a recorrência de questões complexas como a necessidade de se conferir racionalidade à história (constituída agora por um conjunto de acontecimentos não passíveis de repetição). ${ }^{8} \mathrm{~A}$ fundação histórica do conhecimento passou a se localizar fundamentalmente no plano da práxis e do mundo vivido. Não casualmente, portanto, o programa do materialismo histórico, anunciado por Marx em A Ideologia Alemã, e reiterado no prefácio da Contribuição à Crítica da Economia Política, constitui um exemplo paradigmático dessa nova forma de problematização.

Ao analisar a massa dos acontecimentos que constituem a história, Marx visualizou duas grandes regiões articuladas, de cuja determinação recíproca resulta a figura de um todo único e inteligível: uma infra-estrutura, a instância da economia; e, uma super-estrutura, a esfera das representações ideológicas, dos valores morais, das normas 
jurídicas e das idéias políticas. No programa marxiano, o trabalho (enquanto atividade orientada que modifica o em-si da coisa, dandolhe forma e conteúdo) emerge como condição natural da qual os homens não podem escapar, haja vista a mediação das relações entre o homem e a natureza na busca de satisfação das suas necessidades. Canalizando essa atividade, os instrumentos de trabalho estabeleceriam um laço entre o movimento teleológico do trabalho e o determinismo da natureza.

Nessa perspectiva, Marx constitui o trabalho como uma pura positividade econômica, um a priori histórico, condição transcendental de toda forma de sociabilidade possível entre os humanos. Ele tornou a própria representação do trabalho como "valor" algo extrínseco à história. $\mathrm{O}$ modelo de sociabilidade implicado no paradigma da produção perde conteúdo normativo, uma vez que não consegue relacionar o "tipo paradigmático de atividade do trabalho ou da elaboração de produtos e o conjunto de todas as formas restantes de exteriorização cultural dos sujeitos capazes de agir e falar" (Habermas, 2000, p. 114). Ao instalar o ponto de ancoragem da história em uma instância determinada (a esfera econômica), esse programa deixou-se imobilizar pelo movimento identitário do servalor-representação, subsumindo o fato do social comportar uma espessura ontológica não redutível à coisa e seus atributos fenomênicos, quer dizer, materiais.

Os objetos sociais não são coisas, em sentido estrito, mas relações que podem estar sendo mediatizadas pelas coisas, mas também pelas representações e por toda sorte de fantasmagorias. Para conferir à necessidade do trabalho a forma da lei (universal e necessária), o materialismo histórico precisou reportá-la a falta originária que acomete as sociedades dos homens e ao seu modo próprio de responder a esta falta constitutiva. Resposta que, como ressalta Domingues (1991, p. 309), é contingente já que para sua determinação não basta "aferrar-se ao esquema das forças produtivas e isolar aquelas notas gerais que em sua universalidade qualificam o trabalho e são válidas para todas as sociedades históricas possíveis, mas (seria) preciso acrescentar os princípios de sua variação e as notas particulares afetas a cada uma, elas próprias variáveis". 
A ontologia marxista permaneceu, portanto, tributária da normatividade da ontologia herdada da modernidade. A ontologia herdada, diz Castoriadis (1982), só consegue vislumbrar a ontologia como determinação, onde o real existe como algo determinado e esta determinação só pode ser compreendida mediante uma apreensão lógica do existente. A visão do real como algo determinado, leva fatalmente a conclusão de que o real se explica no racional, e o racional se manifestaria como real. ${ }^{9}$ Porém, é possível questionar essa forma de abordar à dimensão da ontologia.

Nesse contexto, o ser humano antes de pensar logicamente as coisas, as imagina. A pessoa e o social-histórico, de forma motivada, selecionam determinadas imagens e as instituem de um sentido específico. Este é propriamente o sentido ontológico. Esse é o pano de fundo que permite compreender que uma condicionalidade propicia uma dada forma, mas essa condicionalidade é sempre parcial. As determinações (descrições nascidas a partir da sociedade que se institui sobre o estrato natural) revelam sempre uma decisão ontológica sobre aquilo que é e também sobre como é. Desse modo, a sociedade se auto-institui mediante um julgamento e uma escolha. Julgamento e escolha que aparece, do ponto de vista político, ou seja, de um projeto de democracia radical, como uma questão vital (Caillé, 2002).

Por conseguinte, a análise da validade dos condicionantes do fato social exige, dentre outras coisas, assumir a incondicionalidade ontológica da história vista como uma totalidade acêntrica ou, se se preferir, de múltiplos centros. Ou seja, exige pensar o social como um conjunto de relações, tanto físicas como intelectuais, com a natureza, com os objetos e com as outras pessoas.

Esse tipo de fundamentação ontológica dessubstancializa o "ser social", pois o social é uma criação permanente, uma criação que se dá a partir de certos elementos estáveis e até invariantes, de modos básicos de com-vivência. Como argumenta Oliva (1999, p. 221), "quando se ingressa em redes de convivência não há, de um lado, um meu e, de outro, a realidade social. O que há é um tipo especial de referência que faço a mim mesmo: refiro-me a mim mesmo na perspectiva do outro, da instituição, ou refiro-me ao outro, à instituição, sob a ótica do que consigo neles ver". 
Nesse sentido, nem o holismo nem o individualismo conseguem dar conta da complexa auto-referencialidade contextual imbricada na vida associativa. No máximo, o que se consegue é vislumbrar a representação da ação pelos atores e não a ação em seu fundamento. Isso só pode ser obtido mediante um tratamento adequado da natureza do vínculo social, mediante a introdução de um outro nível de análise nas ciências sociais (para além do indivíduo e da sociedade). Um nível metametodológico ou, se se preferir, transmetodológico: o nível das redes e das relações que configuram a sociabilidade.

\section{A dádiva como operador simbólico das redes sociais: esboçando uma metodologia de análise}

A chamada "teoria da troca de dádivas" tem uma resposta plausível para os problemas postos acima. Em primeiro lugar, para os difusores do paradigma é possível, sim, "ir-além-da-modernidade", transcender o seu horizonte histórico, sem cair nas aporias performativas do pessimismo melancólico diante da crise da modernidade. Os pensadores da dádiva sugerem que esta crise ao invés de promover a implosão generalizada do social estaria permitindo a criação inédita de uma concepção radicalmente política da sociedade. Os argumentos utilizados para sustentar essa possibilidade ancoram-se, em primeiro plano, na "questão do simbólico".

A discussão em torno da dimensão simbólica da ação social, operada no interior do paradigma da dádiva, permite ressignificar, em outras bases, a questão da fundamentação ontológica do social, sem com isso despolitizar a tarefa interpretativa das ciências sociais. Como sinaliza Caillé:

Imperceptivelmente, discutindo a concepção maussiana do simbolismo acabamos depreendendo aquilo que constitui o seu coração, a questão da aliança. Ora, esta não é outra senão a do político (...). É com relação a esta concepção de conjunto, enriquecida pela perspectiva do político, esta opção por uma constituição determinada, que se deveria agora desenvolver a questão dos laços entre dom e simbolismo. (p. 250-252)

Para isso, é preciso lembrar que o simbólico, para esse paradigma, embora resulte de uma construção em torno da qual vão 
se ancorar as representações do mundo social, não se confunde com estas. A realidade social-histórica não é, ela mesma, uma representação, e, portanto, não pode ser captada como pura causação ou puro encadeamento de sentido (como querem os positivistas/ funcionalistas e os estruturalistas). O simbolismo se enraíza, simultaneamente, no natural, no histórico e no racional. Mais: o simbolismo pressupõe a capacidade de criação, por excelência, do social. Como lembra Burity, a diferença da postulação do caráter simbolicamente construído de toda ordem social, em relação às análises tradicionais, reside na "insistência" em manter juntos o "real racional" e o "simbólico discursivo", chamando a atenção para

o vínculo entre cultura e condições sócio-históricas, por um lado, entre crenças e práticas mediadas culturalmente, por outro, é um objeto de análise e não um a priori indiscutível. Isto impede de se recair na mera dedução de práticas sociais a partir da estrutura analiticamente delimitada (mas dotada de uma objetividade e uma autonomia externas à análise), de se postular uma relação puramente reflexa entre as práticas culturais e as condições materiais existentes, bem como de assumir um voluntarismo analítico, para o qual não existem estruturas ou condicionantes da ação senão o permanente estado de fluxo incontido e avesso a qualquer regularidade. (Burity, 2002, p. 37-38)

Esquecer essa questão, dizem os maussianos, é estabelecer uma multiplicidade de práticas articulatórias como "fatos brutos", quer dizer, fatos sobre os quais não haveria nada a dizer (e menos ainda a fazer), eliminando-se a questão histórica por excelência: a própria gênese de novos sistemas de significação que se cristalizam. ${ }^{10} \mathrm{O}$ uso de uma noção radical de simbolismo funciona como uma espécie de matriz para um rigoroso sistema conceitual capaz de levar às últimas conseqüências a natureza da investigação sociológica, já que a descoberta da coextensividade entre o simbólico e o sistema social da dádiva "faz cair" as oposições clássicas entre o sociológico e o psicológico, entre o social e o individual (Caillé, 1998). Seguindo Mauss, o paradigma insiste na imbricação entre as dimensões utilitárias e simbólicas, propondo uma análise ancorada na gradação e na tradução recíproca entre o social e o individual, uma vez que os simbolismos constitutivos de um plano são passíveis de tradução nos do outro. 
Dessa forma, é possível distinguir três níveis de análise na explicitação da gênese do laço social:

o nível microssociológico da aliança (ad-liança) entre as pessoas, o nível mesossociológico da aliança das pessoas com grupos ou destes com outros grupos, e o nível macrossociológico, o da relação das pessoas e dos grupos, e grupos de grupos, com a totalidade simbólica que forma. O operador do primeiro é o dom, o do segundo aquilo que se poderia designar como ad-sociação, e o registro próprio do terceiro que é o do político. (Caillé, 2002, p. 252-253)

Mas é importante reter a idéia da indissociabilidade desses níveis, uma vez que cada um funciona como uma espécie de interpretador dos outros. Essa é a chave da dimensão simbólica no paradigma da dádiva. A compreensão de que os símbolos só têm vida e significação enquanto "metaforizam" o dom, a associação e o político em um esquema complexo e indeterminado de retradução recíproca. ${ }^{11}$

Isso acontece porque, no sistema de prestação de dádivas, os bens que circulam no espaço social são sempre bens qualitativamente singulares, valorizados segundo padrões anti-econômicos, ou para ser mais exato: segundo padrões simbólicos. Os interesses e as estratégias dos agentes sociais não se reduzem aos valores prevalecentes no campo econômico, uma vez que a troca de dádivas se constitui como um fluxo inter e intracultural, através de um regime de valorização distinto do praticado na esfera estritamente mercantil.

Do ponto de vista metodológico, isso significa que os fatos sociais não podem ser considerados como "coisas". Os fatos sociais tornam-se totais. Um fato social total atravessa todas as esferas da prática. Por isso,

esse princípio não tem um alcance apenas metodológico, mas sócioontológico. Não mais se dirá que se deve tratar os fatos sociais 'como se fossem coisas', subentendendo 'quando sabemos perfeitamente que não o são', e sim que se deve tratar os fatos sociais como símbolos, porque sabemos perfeitamente que é essa, na verdade, a sua natureza. (Caillé, 1998, p. 5)

Disso decorre uma concepção da causalidade social, que denominamos de "metametodológica", porque não se deixa enredar 
pelos determinismos objetivistas, introduzindo a problemática da determinação no âmbito da liberdade. Essa "obrigação da liberdade" implica que se deve deixar de apenas tentar explicar a relação social, para buscar também compreendê-la e interpretá-la.

Compreender e interpretar a ação social significa, nos termos da própria ação social concreta, estabelecer (descrever) as relações que os atores contraem em seu estado nascente, ou seja, no momento mesmo em que se submetem ao arbítrio da lei dos símbolos que eles próprios criam e põem para circular. Pois, é nessas relações que os atores produzem, a um só tempo, sua individualidade, sua comunidade e o conjunto social no qual se movimentam.

Por essa via, o paradigma da dádiva dilui os modos clássicos de operar as categorias metodológicas, haja vista que tanto o individualismo como o holismo tendem a funcionar com redutores analíticos: o interesse dos atores ou a interiorização das normas (Godbout, 2002). A razão explicativa para uma determinada prática ou ação é sempre buscada em um condicionante, determinado em última instância, seja a agência, os valores, as funções ou a estrutura.

$\mathrm{O}$ paradigma da dádiva, ao contrário, não decide a priori o móvel da ação. Essa é acessada mediante um conjunto complexo de operadores irredutíveis uns aos outros. A própria dádiva, aliás, atua como um operador simbólico que funciona mediante incondicionantes, eles mesmos condicionais, na criação de oposições ilusórias (macro $\mathrm{x}$ micro, objetivo x subjetivo). Desse modo, é sugestiva a orientação de Martins (2003), um dos principais difusores do paradigma da dádiva no Brasil, para que se busque compreender as práticas sociais pelo entendimento do surgimento dos vínculos sociais, os quais estariam articulados às formas pelas quais uma sociedade específica faz circular seus bens simbólicos.

No âmbito metodológico, isso implica a delimitação de quatro critérios de análise dos sistemas sociais: a descriptibilidade, a compreensibilidade, a interpretabilidade e a praticidade. Onde a descriptibilidade envolve a capacidade de descrição objetiva da lógica de circulação dos bens sociais, nos diferentes níveis micro, meso e macrossociológico de sociabilidade elencados por Caillé (2002). A compreensibillidade refere-se à compreensão dos motivos e 
significações das práticas (nos termos weberianos). A interpretabilidade retoma a capacidade de interpretação crítica da imaginação sociológica (Mills) e de retradução dos fenômenos sociais (Ricouer). E, por fim, a praticidade articula a crítica social com os imperativos políticos e normativos da emancipação social (Martins, 2002, p. 3).

Nesse sentido, pensar a prática social não significa, nesse paradigma, reduzi-la aos seus acontecimentos empíricos, não obstante exista também a necessidade de se partir dos dados empíricos para se produzir uma reflexão sociológica efetiva.

O que deve ser enfatizado, no trabalho de resgate das memórias culturais, das significações simbólicas e das lógicas institucionais, é a tentativa de ir além das oposições binárias, pois essas oposições são impeditivas de uma melhor apreensão das redes de práticas que organizam a ação social. Ao invés de opor a objetividade das estruturas e a subjetividade das representações, a teoria da dádiva busca articular as diversas modalidades da relação ao mundo social que (de)marcam a existência das redes sociais que vinculam os atores entre si e entre estes e as instituições. Com isso, descartam-se as antigas concepções correspondentistas da verdade enquanto representação do real.

Dessa forma, o uso de determinados instrumentos de pesquisa não assume, no paradigma da dádiva, um caráter meramente técnico. Mas, encontra-se associado aos próprios objetivos da investigação que se pretende levar a termo, uma vez que não há aqui nenhuma pretensão de alimentar mais um fantasma dicotômico presente nas ciências sociais: a infeliz distinção entre métodos quantitativos e qualitativos. A teoria da troca de dádivas tem o mérito de deixar mais claro o uso que fazemos de determinadas categorias, nas nossas práticas investigativas, para organizar, classificar e explicar/ compreender o mundo social.

Como o próprio "dado" (quantitativo ou qualitativo) é tratado como uma representação simbólica, assimilado pelo imaginário social como a memória de uma articulação (entre representação e realidade) que envolve um complexo dinamismo associativo, ele funciona como uma estratégia de classificação e ordenamento dos fenômenos, fixando-se em premissas ontológicas e instrumentalizando o 
reconhecimento do evento. Assim, mais do que conferir um caráter de objetivação à observação, a ênfase reside na identificação dos condicionantes (a solidariedade do dom, o interesse mercantil ou a obrigação burocrático-racional) da rede que está sendo objeto de estudo (Martins, 2003).

Ao reconhecer o caráter simbolicamente construído de toda ordem social, torna-se possível lidar, metodologicamente, com a indeterminação relativa das ordens e dos contextos que configuram a existência do social (Caillé, 1997). As categorias analíticas são conceitualizadas como categorias práticas, podendo ser utilizadas conforme o eixo de análise priorizado na investigação: a instituição, o indivíduo, os grupos, os sistemas de poderes, etc., deslocando assim o debate epistemológico entre validade e sentido na construção do conhecimento social. Reconhece-se, então, que

o sentido, a significação, a idealidade são criadas para a sociedade; a validade também. A distinção sentido/validade é constitutiva da instituição da sociedade. Ela é o pressuposto das distinções correto/ incorreto, lícito/proibido, etc. (...) Mas essa distinção é totalmente insuficiente. Uma outra questão, muito mais grave, surge a partir do momento em que reconhecemos, como somos obrigados a fazer, que cada sociedade cria, não somente o que para ela tem sentido, mas também o que para ela é validade e válido. (Castoriadis, 1999, p. 44)

Logo, no plano normativo, as categorias analíticas tendem a funcionar como indicadores provisórios para validar e avaliar os resultados dos processos sociais investigados. Elas permitem entrever, por um lado, a lógica identitária do instituído e, por outro, os processos instituintes da ação social dos atores, ou, nos termos defendidos por Martins (2003), identificar os tipos e o grau de interatividade da dádiva nos sistemas sociais complexos.

\section{Considerações finais}

O que podemos, enfim, extrair de uma sociologia da prática social inspirada na troca de dádivas? Acima de tudo, a idéia de que não precisamos abandonar uma fundamentação ontológica para o "ser social". Pois, não se pode exercer o pensamento, principalmente o 
pensamento crítico, sem que seu próprio discurso tenha algum tipo de fundamento. Como validar o pensar, no discurso, sem critérios objetiváveis, ou seja, sem retornar ao irrealismo e sem fazer a defesa silenciosa do relativismo?

É possível, sim, validar uma ontologia histórica radicalmente distinta daquela que vem sendo forjada pela tradição ocidental e ancorada exemplarmente no discurso da modernidade e nas aporias da racionalidade utilitária. Uma ontologia histórica, mas não historicista, que seja capaz de nos propor uma outra relação com a verdade que emana das pesquisas sociológicas.

Mais ainda. Compreende-se que nem toda relação social é arbitrária, os sistemas de signos não podem representar tudo. Logo, o real não é completamente representável, uma vez que há resíduos que não podem ser autenticados no quadro geral do saber. Não obstante, a dissolução dos quadros da representação não precisa esgotar os regimes de práticas possíveis, o que significa dizer que o objeto das ciências não está ligado nem às coisas em si nem a uma subjetividade auto-centrada. O objeto social é constituído no intermezzo como uma rede de relações.

Parafraseando Rajchman (1987, p. 69), podemos, finalmente, com o paradigma da troca de dádivas, pôr de lado “'as promessas mescladas de dialética e antropologia', e criar assim uma espécie diferente de 'teoria crítica' [que] não é hegeliana na medida em que a realização de uma sociedade racional não é o seu objetivo; e não é kantiana”, uma vez que não se assume um universalismo abstrato.

Com a crítica da razão utilitária nos defrontamos com uma transformação da crítica metodológica nas ciências sociais de modo que se torna possível viabilizar, em nossas pesquisas, um modo de exercício da liberdade que é real e não meramente fundacional. Uma liberdade capaz de diluir as redes de práticas instituídas que emprestam substância à nossa natureza individual, comunitária e social-histórica, mas sem prescindir de um sentido (possibilidade) para a criação de novas práticas pelos atores sociais concretos. 


\section{Notas}

1 Assim como Heidegger insiste na idéia de uma metaontologia que visa a analítica da temporalidade do ser (Erber, 2003, p.33), cujo caráter constitutivo é sua determinação como "ser-com", a defesa de uma metametodologia para captar o "ser social" não marca uma recaída na busca de um princípio universal metafísico, estruturando-se antes ao nível da (in)determinação ontológica do político em seu acontecer concreto nas várias modalidades associativas que engendram o vínculo social.

2 A proposta de Kant consistia exatamente em estabelecer a metafísica como ciência: ciência do ser, ou seja, investigação última do que existe. Para isso, ela não poderia se identificar com investigações empíricas. Ela deveria formular proposições cujo conteúdo de verdade fossem independentes do que o mundo é (não passíveis de verificação empírica). Proposições (sintéticas e a priori) que fossem, elas mesmas, condições do conhecimento empírico (Oliveira, 1996).

3 Em um trabalho anterior, tentei argumentar que ao apontar para a tensão entre ontologia e ciência é possível compreender, dentre outras coisas, o debate recente entre naturalistas e anti-naturalistas, bem como as divergências sobre a adoção de determinados modelos explanatórios na explicação dos processos sociais (Freitas, 2002).

4 Não temos a intenção, neste trabalho, de problematizar a questão relativa ao estatuto da "pós-modernidade", ou seja, não pretendemos discutir se estamos na presença de uma descontinuidade radical, ou se simplesmente teríamos uma forma neoconservadora de dissolução do sujeito social e epistêmico pela atomização dos jogos de linguagem tecidos em variadas colchas de retalhos remendados no contexto localizado de cada ciência particularizada. Sobre esse aspecto, veja-se o trabalho de H. Bhabha (2001), principalmente o capítulo I - O Compromisso com a Teoria - e o capítulo IX - O Pós-Colonial e o Pós-Moderno: A Questão da Agência.

5 Presente nos diferentes projetos positivistas que acompanharam a trajetória da episteme moderna, de A. Comte a S. Mill, esse modelo ajudou a introduzir a figura de um sujeito intervencionista capaz de sintetizar os "fatos brutos" da experiência, antes de toda interpretação, fazendo com que o real passasse a ser reduzido destas duas "empiricidades", a riqueza e o estado. Ambas compreendidas, exemplarmente, no homo oeconomicus de A. Smith e no homo politicus de Montesquieu (Oliveira, 1999).

6 Entretanto, é possível inferir algumas dificuldades com essa idéia, particularmente no que se refere à natureza da justificação requerida para 
a crença verdadeira equivaler a conhecimento também verdadeiro. Ela nos diz que $\mathrm{S}$ pode justificar sua crença em $p$ somente quanto a possibilidade da falsidade de $p$ estiver excluída. O problema é precisamente saber que a justificação de alguém para acreditar que $p$ não conecta com a verdade de $p$ de um modo correto. O que é preciso, então, é um quadro claro de "crença justificada"; e nesse percurso mostrar a conexão entre justificação, de um lado, e crença e verdade, de outro (Grayling, 2002, p. 1-segs.).

7 Influência marcante nessa "dobra" da cadeia da natureza ao tempo foi dada, sem dúvidas, pela ruptura com o princípio da constância do ser (fixismo), por Darwin e Lamarck, substituindo as categorias mecanicistas pelas categorias orgânicas.

8 As primeiras tentativas de fornecer uma solução plausível para esses problemas assumiram feições distintas no pensamento de Hegel e Marx (dialética), Dilthey (hermenêutica da compreensão) e Nietzsche (genealogia).

9 Para Castoriadis, a visão do ser como algo determinado, ou como ele prefere chamar a "ontologia da determinação", ela mesma uma criação social e histórica derivada da tradição greco-ocidental. A lógica e a ontologia da determinação manifestam-se de forma paradigmática na teoria dos conjuntos, onde os objetos são definidos e suas relações surgem a partir de uma gama combinatória possível e delimitada. Ou seja, a teoria dos conjuntos pressupõe a constituição prévia de um conjunto de operações (lógicas) específicas para definir objetos (não importa qual seja a sua natureza): distinguir, separar, juntar, contar. Daí ele denominar essa forma de operar de lógica conjuntista-identitária, pois ela pensa o objeto enquanto definido por seus atributos. O elemento fica definido por aquilo que se considera essencial para pertencer a um determinado conjunto. De forma concomitante, se exclui aquilo que resulta acidental e portanto prescindível para sua pertença em um conjunto determinado. O ser da realidade, nesse contexto, estaria contido na essência inerente a cada ente concreto. Teríamos, assim, a expressão da lógica de identidade. Nela o conceito constitui a revelação da essência, fazendo do pensar um reflexo do ser. Essa lógica da identidade (e sua respectiva ontologia) balizou, de uma forma quase hegemônica, a reflexão sobre o ser na história do pensamento ocidental, pressupondo um conjunto amplo de categorias que serviram para determinar o ser em geral e os entes em particular, tais como: totalidade, unidade, realidade, necessidade. Todas essas categorias passaram a delimitar o princípio material e o princípio formal do ser, enquanto elementos constitutivos da substância. Nesse sentido, na lógica 
e na ontologia de determinação, o sentido emerge pré-determinado por algo que fundamenta a explicação última sobre a realidade. Ver $A$ Instituição Imaginária da Sociedade (1982).

10 Desse modo, definir a hegemonia como uma "forma de política", e não como um "lugar determinável na topografia do social", como fazem Laclau e Mouffe (1985) implica uma rejeição explícita da ontologia. Isso porque, segundo eles, a ontologia inscreveria a hegemonia como "centro" do social, ou seja, como sua essência, fazendo retornar, portanto, o projeto fundacionalista. O problema, no entanto, é que com essa "estratégia" o social também deixa de ser redutível a qualquer princípio. Mais ainda, a própria idéia do "social" deixa de fazer sentido. Sua visão da indeterminação da realidade só permite que se possa falar em criação (e autonomia) do social de um modo metafórico.

11 Martins (2003) "traduz" essas dimensões em três diferentes níveis da ação social: o nível da reflexividade prática ou "senso comum", o nível da reflexividade institucional ou sócio-histórica e o nível da reflexividade expressiva ou simbólica. No primeiro nível, teríamos o modo como os atores sociais (individuais ou grupais) expressam seus modos de inserção social, sendo captados no âmbito das representações e do habitus. No segundo nível, teríamos indicado o contexto macro-social e histórico de onde emergem as representações do primeiro nível que, por sua vez, são captadas nos dispositivos normativos de regulação das condutas sociais. E, por fim, no terceiro nível, teríamos a dinâmica propriamente simbólica do fenômeno social, podendo ser apreendida tanto pelas narrativas simbólicas que fornecem sentido à ação social, como pelas significações das práticas intersubjetivas concretas.

12 Ponto nodal da crítica de Habermas que acusa as teorias pós-modernas de serem nominalistas e empiristas, impedindo a inteligibilidade e mergulhando na contingência.

Abstract: In this article, it tries to demonstrate that the critic of the utilitarian reason, processed by the paradigm of the gift contributes for a radical reflection of the methodological choices in the extent of the social sciences. When one inteds to interrogate the social bond, the gift paradigm sets a third level of analysis of the social action in motion: the level of the nets and of the relationships. In the extent ontologic, that allows the sociological theories to transcend, simultaneously, the dilemm as of the holism and of the methodological 
individualism, opening new description ways, explanation, interpretation and evaluation of the operation of the rules of the social.

Key-words: utilitarian reason, Ontology, Epistemalogy of Social Networks.

Résumé: Dans cet article, il essaie de démontrer que la critique de la raison utilitaire, a traité par le paradigme du don contribue pour une réflexion radicale des choix méthodologiques dans l'ampleur des sciences humaines. Quand chercher pour interroger l'attache sociale, le paradigme du don il travaille un troisième niveau d'analyse de l'action sociale, le niveau des réseau et des rapports. Dans l'ampleur ontologique, cela permet aux théories sociologiques de transcender, simultanément, les dilemmes de l'holi sme et de l'individualisme méthodologique, ouvrir nouvelles routes de la description, explication, interprétation et évaluation de l'opération des règles du social.

Mots-clés: raison utilitaire, Ontologie, Epistemologie des Réseaux.

\section{Referências bibliográficas}

BURITY, J. (Org.). Cultura e identidade: perspectivas interdisciplinares. Rio de Janeiro: DP\&A, 2002.

CAILLÉ, A. Antropologia do dom: o terceiro paradigma. Petrópolis, RJ: Vozes, 2002.

CAILLÉ, A. O princípio de razão, o utilitarismo e o antiutilitarismo. Sociedade e Estado, v. 16, n. 1-2, p. 26-56, 2001.

CAILLÉ, A. Nem holismo nem individualismo metodológico: Marcel Mauss e o paradigma da dádiva. Revista Brasileira de Ciências Sociais, São Paulo, 1998.

CAILLÉ, A. A demissão dos intelectuais. Lisboa: Instituto Piaget, 1993.

CASTORIADIS, C. Socialismo ou barbárie: o conteúdo do socialismo. São Paulo: Brasiliense, 1982.

CASTORIADIS, C. A instituição imaginária da sociedade. Rio de Janeiro: Paz e Terra, 1995.

CAPES-COFECUB. Anto-utilitarismo e mercantilização: que solidariedades para quais democracias? Plano de trabalho 2002-2003. Brasil-França, 2002. 
DOMINGUES, I. O grau zero do conhecimento: problema da fundamentação nas ciências humanas. São Paulo: Loyola, 1991.

DOSSE, F. O império do sentido: a humanização das ciências humanas. Bauru, SP: EDUSC, 2003.

ERBER, P. Política e verdade no pensamento de Martin Heidegger. São Paulo: Loyola, 2003.

FREITAS, A. S. A navalha de Ockham e o problema da fundamentação metafísica das princípios metodológicos da Ciência. Recife: UFPE, 2002. Mimeogr.

GODBOUT, J. Introdução à dádiva. Revista Brasileira de Ciências Sociais, São Paulo, 1998.

HABERMAS, J. O discurso filosófico da modernidade. São Paulo: Martins Fontes, 2000.

HEIDEGGER, M. Carta sobre o humanismo. São Paulo: Moraes, 1991.

HENWOOD, K. L. Qualitative inquiry perspectives, methods and psychology. In: RICHARDSON, J. T. (Org.). Handbook of qualitative research methods. Leicester: BPS Books, 1996.

LACEY, H. Valores e atividade científica. São Paulo: Discurso Editorial, 1998.

LACLAU, E.; MOUFFE, C. Hegemony and socialist strategy. London: Verso, 1985.

LECHTE, J. 50 pensadores contemporâneos essenciais: do estruturalismo à pós-modernidade. Rio de Janeiro: DIFEL, 2002.

LEFORT. C. Pensando o político: ensaios sobre democracia, revolução e liberdade. Rio de Janeiro: Paz e Terra, 1991.

MARTINS, P. H. Metodologia para o estudo do sistema social da dádiva. Recife: UFPE, 2003. Mimeogr.

MARTINS, P. H. (Org.). A dádiva entre os modernos: discussão sobre os fundamentos e as regras do social. Petrópolis, RJ: Vozes, 2002.

OLIVA, A. Conhecimento e liberdade: individualismo x coletivismo. Porto Alegre: EDIPUCRS, 1999.

OLIVEIRA, N. F. Tractatus ethico-politicus: genealogia do ethos moderno. Porto Alegre: EDIPUCRS, 1999.

OLIVEIRA, M. A. Reviravolta lingüístico-pragmática na Filosofia contemporânea. São Paulo: Loyola, 1996. 
OLIVEIRA, M. A. Para além da fragmentação: pressupostos e objeções da racionalidade dialética contemporânea. São Paulo: Loyola, 2002.

PERRUSI, M. S. A instituição social-histórica da autonomia como criação ontológica em Castoriadis. Recife: CFCH, 1998. Dissertação (Mestrado).

RAJCHMAN, J. Foucault: a liberdade da filosofia. Rio de Janeiro: Jorge Zahar, 1987.

RORTY, R. Ensaios sobre Heidegger e outros escritos filosóficos 2. Rio de Janeiro: Relume Dumará, 1999.

RUIZ, C. Idéias para uma Ontologia da Indeterminação. Perspectiva Filosófica, Recife, v. 7, n. 16, 2001.

SARTORI, G. A política: lógica e método nas ciências sociais. Brasília: UnB, 1997. 